\section{Consumer Color Preferences for Single-stem Cut Flowers on Calendar Holidays and Noncalendar Occasions}

\author{
Chengyan Yue ${ }^{1,3}$ \\ University of Minnesota-Twin Cities, Horticultural Science and Applied \\ Economics, 1970 Folwell Avenue, St. Paul, MN 55108 \\ Bridget K. Behe ${ }^{2}$ \\ Department of Horticulture, Michigan State University, East Lansing, MI \\ 48824
}

Additional index words. marketing, sociodemographics, flower attributes

\begin{abstract}
Flower color is a dominant attribute of fresh flowers, likely playing a key role in purchase preference. Several prior studies showed flower color preference differed by gender, but other information on color preferences is sparse. Data for this study were collected by the Ipsos-National Panel Diary Group for the American Floral Endowment, which maintained an extensive panel of consumer transactions from 1992 to 2005, including floral purchases. Multinomial logit analysis of single-stem cut flower purchases showed that men and women differed in their cut flower color preferences but that flower color preference also varied with demographic characteristics and by occasion. We grouped colors into six categories: BluePurple, RedBronze, PeachPink, White, Yellow, and Other. The highest percentage of flowers purchased were RedBronze $(34 \%)$, whereas the lowest percentage of flowers were Yellow (10.01\%) with Other flower colors accounting for less than $5 \%$ of purchases. Although women used a more diverse color palette, both men and women were more likely to buy RedBronze flowers for an anniversary and buy PeachPink flowers for Mother's Day. Between 1992 and 2005, women were less likely to purchase PeachPink flowers and men were less likely to purchase RedBronze over time. Overall demand for BluePurple and Yellow flower colors increased over time, whereas the demand for other color categories decreased over time.
\end{abstract}

Fresh cut flowers can be given as gifts at many different holidays and occasions. The wholesale value of domestic cut flower production was \$403 million in 2008 (USDA, 2009). Still, imported cut flowers account for a greater percentage of U.S. sales; in 2003 (most recent available data), the value of imported cut flowers was $\$ 611$ million, but domestic production was valued at $\$ 425$ million (USDA, 2005). Flowers promote self-esteem and satisfy the need for aesthetically pleasing surroundings (Krech et al., 1969). Recent studies reinforced the premise that flowers and plants have psychological, emotional, behavioral, and environmental benefits. Haviland-Jones et al. (2005) found that flowers as gifts had positive effects on people's emotion, mood, social behavior, and even immediate and long-term memory.

Flower color is a primary product attribute for combination planters (Mason et al.,

Received for publication 19 Aug. 2009. Accepted for publication 8 Oct. 2009.

We sincerely acknowledge American Floral Endowment's generous offer of the access to the Consumer Tracking Study data set.

${ }^{1}$ Assistant Professor and Bachman Endowed Chair in Horticultural Marketing.

${ }^{2}$ Professor

${ }^{3}$ To whom reprint requests should be addressed; e-mail yuechy@umn.edu. red roses were particularly appropriate to convey the messages "I love you" and "I apologize," but three yellow carnations and three white daisy sprays were inappropriate in conveying these messages. Birren (1940, 1972, 1988) associated different flower colors with different personalities: longwavelength colors such as red and orange indicate extroverted personalities and shortwave colors such as blue and violet indicate introverted personalities. Red is a commonly used color at Christmas and most consumers preferred red poinsettias (Redman et al., 1997).

A better understanding of consumers' preferences for cut flower colors and their purchasing patterns and behaviors at various calendar holidays and noncalendar occasions can help retailers more effectively merchandise certain flower colors for certain events and potentially increase their sales, market share, price per transaction, or profitability. However, there is little insight with regard to consumer choices of flower colors at different calendar and noncalendar occasions. This study helps to fill this gap.

Consumers' choice of different colors is motivated by and depends on the flower receivers' (buyer's own or gift recipients') latent degree of satisfaction that is derived from the particular colors at different occasions (Greene, 2002; Yue and Behe, 2008). In theory, consumers chose the flower color that gave the giver and recipient the highest latent degree of satisfaction. Although latent satisfaction cannot be observed, flower color choice can be.

\section{Materials and Methods}

2008), edible flowers (Kelley et al., 2001, 2002), geraniums (Behe et al., 1999), and poinsettias (Redman et al., 1997). Robertson and Chatfield (1982) published some of the early consumer research that provided evidence that red flower color was preferred by men and pastel colors by women. This was especially true for roses (Hutchison and Robertson, 1979). Both men and women preferred red geraniums (Behe et al., 1999) and poinsettias (Redman et al., 1997), but there was a significant market for a hypothetical blue geranium (Behe et al., 1999).

Consumers have attributed meanings and symbolism to flower colors and they use different flower colors to convey different feelings, which somehow may guide consumers' choice of different colors of flowers at different occasions. Attributing meaning to certain flower colors may have begun in Victorian times. Traditionally, red has conveyed passionate love and affection; pink-grace, gentility, and happiness; orange-energy, enthusiasm, and warmth; purple-dignity, pride, and success; white-innocence, humility, and reverence; yellow-joy, lightheartedness, and friendship; and blue-peace, openness, and serenity (Anonymous, 2008). Doyle et al. (1994) studied how people connected six meanings with particular arrangements of flowers and found that participants reliably associated three arrangements with particular meanings. For instance, three
Data used in this study were collected by the Ipsos-National Panel Diary Group (NPD) for the American Floral Endowment (AFE). NPD maintains an extensive consumer panel from which the AFE collected consumer transactions of floral products from 1992 to 2005. The data included consumers from 48 states and Washington, DC, and their floral purchases were tracked monthly for 13 years. Demographic information about panelists, floral products, floral gift recipients, and flower colors purchased on specific calendar holidays and noncalendar occasions was recorded. Given the 13-year timeframe, large geographic area covered, and large sample size of the study, we consider the data representative of all consumers of floral products in the United States during this time period. Because panel data also allowed us to examine flower color choice over time from 1992 to 2005, there was a longitudinal component to explore.

For this analysis, we grouped the 12 flower colors into six categories based on a combination of color intensity and proximity on the color wheel and to simplify the analysis: BluePurple (blue and purple/violet), RedBronze (bronze/rust, orange, red/ crimson), PeachPink (peach, salmon, and pink), White (white), Yellow (yellow), and Other (other color). 
Because the dependent variables were categorical (six flower color categories), we used a generalized multinomial logit model to estimate the probability of a consumer's choice of different colors (Yue and Behe, 2008; Yue and Tong, 2009). Consumers' satisfaction is derived from choosing a specific color, which relies on measurable factors including the consumers' demographic characteristics, their association of different colors with different symbolic meanings, the calendar and noncalendar occasions of purchase, and whether they purchased for self-use or as gifts. Consumers' demographic characteristics included age, gender, and income.

Previous studies showed that men and women had different color preferences (Ellis and Ficek, 2001).To test the hypothesis that males and females were similar in their flower color choices, we conducted a $\mathrm{z}$-test for the difference between the proportions of males' and females' choice of different flower colors. In addition, the Hausman test was conducted for the two sets of multinomial model coefficients for male and female shoppers. The test statistics follows $\chi^{2}$ distribution with degrees of freedom of number of coefficients estimated. If the hypothesis was not rejected, we would use one multinomial model including both male and female to do the estimation. Otherwise, we would use two multinomial models to estimate male and female buyers' choice of flower colors separately. The maximum likelihood estimation method was used to estimate coefficients using SAS 9.1.3 (SAS, Cary, NC). The cut flower transaction data included bunch and bouquet purchases, single-stem flower purchases, boxed flower purchases, and so on. Only data for single-stem purchases were used in this analysis because a single stem of a cut flower could be associated with a single color, whereas a bouquet or floral arrangement could be comprised of mixed colors. Therefore, using single-stem cut flower transaction data made the analysis of consumers' color choices more accurate.

\section{Results}

The colors included in each category and the frequency and percentage of observations in each category showed that the 24,640 recorded transactions were of flower colors distributed around the color wheel and accounted for $22.09 \%$ of cut flower purchases. In $10.74 \%$ of the transactions (2646), participants bought BluePurple flowers, in $23.77 \%$ of the transactions (5856) PeachPink flowers were purchased, in $39.34 \%$ of the transactions (9693) the participants bought RedBronze flowers, in $11.31 \%$ of the transactions (2788) White flowers were purchased, in $10.01 \%$ of the transactions (2466) the participants bought flowers with Yellow color, and in $4.83 \%$ of the transactions (1191) flowers of other colors were bought. Compared with other colors, the predominant flower color purchased was RedBronze, whereas the flower color purchased least was Yellow.
Table 1 shows the means and standard deviations (SDS) of the explanatory variables that were included in the multinomial logit models. Year was a continuous variable, indicating when the purchase occurred during 1993 and 2005 with a value of 1 = year 1993 and up to $14=$ year 2005. Income was a continuous variable about income of buyers. The mean income of participants was $\$ 61,050$. As for the age of the participants, 26\% were younger than 39 age years, $35 \%$ were between ages 40 and 54 years, and $38 \%$ were aged 55 years or older.

To simplify the analysis, we examined the distribution of purchases among calendar and noncalendar occasions and eliminated occasions with few frequencies (less than 500) and included 11 calendar holidays and noncalendar occasions when most transactions occurred. The noncalendar occasions we included were anniversaries (which accounted for $6 \%$ of all occasion purchases), birthdays $(13 \%)$, cemetery/memorials $(5 \%)$, house warmings and home decorations (25\%), get well occasions $(5 \%)$, expressing love $(8 \%)$, and sympathy/funerals (4\%). The calendar occasions we included were Christmas/Hanukkah (7\%), Easter/Passover (7\%), Mother's Day (8\%), and Valentines' Day (11\%).

The data showed that of the 24,640 transactions, 17,192 of them were made by female buyers and 7,448 of them were made by males; that is, $70 \%$ of the buyers of singlestem flowers were female. This finding is consistent with literature that shows a majority of floral purchases are made by women. Among women, 44\% $(\mathrm{SD}=0.50)$ made purchases for themselves, whereas only $6 \%$ of males $(\mathrm{SD}=0.23)$ made purchases for themselves. Conversely, $56 \%$ of single-stem floral purchases were gifts from women, whereas $94 \%$ of single-stem floral purchases were gifts from men. We captured the purchaser's and recipient's gender for many occasions, but as a result of questionnaire format, we were unable to identify all recipients' gender. For example, for those recipients who were friends, business acquaintances, and relatives, there was no indicator that showed the receivers' gender. For these transactions, the recipients' gender was defined as "unknown." For the transactions in which the recipient's gender was identified, $37 \%$ of the flowers were given to a female and $6 \%$ were given to a male. At least $22 \%$ of female single-stem floral purchases go to female recipients with $34 \%$ intended for decorations and $14 \%$ for birthdays.

The results in Table 2 show that male and female buyers differed in their choice of flower colors. A higher percentage of male shoppers chose RedBronze, but female shoppers were more likely to choose a more diverse flower color palette by purchasing singles stems that were nonred. This finding was consistent with those reported by Robertson and Chatfield (1982).

Examining the data more closely (Table 3), we found that the mean of recipients' gender for male purchases was 0.72 ; that is, $72 \%$ of the purchases made by male shoppers were for female recipients. Twenty-three percent of the purchases made by males were on Valentine's Day and $20 \%$ of their purchases were for the

Table 1. Summary statistics of the explanatory variables used in the multinomial logit models to estimate female's and male's flower color choice on different occasions $(n=24,640)$.

\begin{tabular}{|c|c|c|c|}
\hline Variable & Description & Mean & SD \\
\hline Year & $1=1993,2=1994, \ldots 14=2005$ & 8.43 & 3.87 \\
\hline \multicolumn{4}{|l|}{ Buyer's sociodemographics } \\
\hline Income $^{\mathrm{z}}$ & Buyer's income in $\$ 1000$ & 61.05 & 36.87 \\
\hline Age younger than 39 years & $\begin{array}{c}\text { Buyer's age was } 39 \text { year and younger, } \\
1=\text { yes, } 0=\text { no }\end{array}$ & 0.26 & 0.44 \\
\hline Age $40-54$ years & $\begin{array}{l}\text { Buyer's age was between } 40 \text { and } 54 \text { years, } \\
1=\text { yes, } 0=\text { no }\end{array}$ & 0.35 & 0.48 \\
\hline Age 55 years and older & $\begin{array}{l}\text { Buyer's age was } 55 \text { years and older, } \\
1=\text { yes, } 0=\text { no }\end{array}$ & 0.38 & 0.49 \\
\hline \multicolumn{4}{|l|}{ Noncalendar occasions } \\
\hline Anniversary & Anniversary, $1=$ yes, $0=$ no & 0.06 & 0.23 \\
\hline Birthday & Birthday, $1=$ yes, $0=$ no & 0.13 & 0.34 \\
\hline Cemetery/memorial & Cemetery or Memorial, $1=$ yes, $0=$ no & 0.05 & 0.22 \\
\hline Decoration & $\begin{array}{l}\text { Home decoration or home warming, } \\
1=\text { yes, } 0=\text { no }\end{array}$ & 0.25 & 0.44 \\
\hline Get well & Get well, $1=$ yes, $0=$ no & 0.05 & 0.23 \\
\hline Love & Love, $1=$ yes, $0=$ no & 0.08 & 0.28 \\
\hline Sympathy/funeral & Sympathy or funeral, $1=$ yes, $0=$ no & 0.04 & 0.19 \\
\hline \multicolumn{4}{|l|}{ Calendar occasions } \\
\hline Christmas/Hanukkah & Christmas or Hanukkah, $1=$ yes, $0=$ no & 0.07 & 0.25 \\
\hline Easter/Passover & Easter or Passover, $1=$ yes, $0=$ no & 0.07 & 0.25 \\
\hline Mother's Day & Mother's Day, $1=$ yes, $0=$ no & 0.08 & 0.27 \\
\hline Valentine's Day & Valentine's Day, $1=$ yes, $0=$ no & 0.11 & 0.31 \\
\hline \multicolumn{4}{|l|}{ Recipient's gender } \\
\hline Unknown & $\begin{array}{l}\text { The recipient's gender was unknown from } \\
\text { the data, } 1=\text { yes, } 0=\text { no }\end{array}$ & 0.57 & 0.50 \\
\hline Female & $\begin{array}{l}\text { The receiver's gender was female, } \\
1=\text { yes, } 0=\text { no }\end{array}$ & 0.37 & 0.48 \\
\hline Male & $\begin{array}{l}\text { The receiver's gender was male, } \\
1=\text { yes, } 0=\text { no }\end{array}$ & 0.06 & 0.23 \\
\hline
\end{tabular}

${ }^{\mathrm{z}}$ In the original questionnaire, income was in eight categories. During the analysis, the midpoints of each category were used to generate a continuous variable. 
Table 2. Test statistics and significance levels for proportion differences of color choices between male and female floral purchasers.

\begin{tabular}{lccc}
\hline Color categories & Female $\hat{\phi}_{1}\left(n_{1}=17,192\right)$ & Male $\hat{\phi}_{2}\left(n_{2}=7,448\right)$ & Test statistics value \\
\hline BluePurple & $12.97 \%$ & $5.60 \%$ & $19.94^{* * *}$ \\
Peachpink & $25.22 \%$ & $20.42 \%$ & $8.38^{* * *}$ \\
RedBronze & $32.42 \%$ & $55.30 \%$ & $-33.76^{* * *}$ \\
White & $13.06 \%$ & $7.29 \%$ & $14.57^{* * *}$ \\
Yellow & $10.99 \%$ & $7.75 \%$ & $8.29^{* * *}$ \\
Other & $5.35 \%$ & $3.64 \%$ & $6.18^{* * *}$ \\
\hline
\end{tabular}

$\mathrm{z}_{z}=\left(\hat{\phi}_{1}-\hat{\phi}_{2}\right) / \sqrt{\frac{\hat{\phi}_{1}\left(1-\hat{\phi}_{1}\right)}{n_{1}}+\frac{\hat{\phi}_{2}\left(1-\hat{\phi}_{2}\right)}{n_{2}}}$ and $* * *$ means significant at the $1 \%$ level.

Table 3. Summary statistics of single-stem flower purchase occasions and flower receivers' genders from female and male givers.

\begin{tabular}{|c|c|c|c|c|}
\hline \multirow[b]{2}{*}{ Variables } & \multicolumn{2}{|c|}{ Female $\left(n_{1}=17,192\right)$} & \multicolumn{2}{|c|}{ Male $\left(n_{2}=7,448\right)$} \\
\hline & Mean & $\mathrm{SD}$ & Mean & $\mathrm{SD}$ \\
\hline \multicolumn{5}{|l|}{ Receiver's gender } \\
\hline Unknown & 0.70 & 0.46 & 0.26 & 0.44 \\
\hline Female & 0.22 & 0.42 & 0.72 & 0.45 \\
\hline Male & 0.07 & 0.26 & 0.02 & 0.14 \\
\hline \multicolumn{5}{|l|}{ Noncalendar occasions } \\
\hline Anniversary & 0.03 & 0.16 & 0.13 & 0.33 \\
\hline Birthday & 0.14 & 0.35 & 0.12 & 0.33 \\
\hline Cemetery/memorial & 0.05 & 0.22 & 0.05 & 0.22 \\
\hline Decoration & 0.34 & 0.47 & 0.06 & 0.25 \\
\hline Get well & 0.06 & 0.25 & 0.03 & 0.17 \\
\hline Love & 0.03 & 0.17 & 0.20 & 0.40 \\
\hline Sympathy/funeral & 0.05 & 0.21 & 0.02 & 0.13 \\
\hline \multicolumn{5}{|l|}{ Calendar occasions } \\
\hline Christmas/Hanukkah & 0.08 & 0.28 & 0.04 & 0.18 \\
\hline Easter/Passover & 0.08 & 0.28 & 0.03 & 0.18 \\
\hline Mother’s Day & 0.08 & 0.27 & 0.08 & 0.28 \\
\hline Valentine's Day & 0.06 & 0.24 & 0.23 & 0.42 \\
\hline
\end{tabular}

expression of love. Female buyers were different with $34 \%$ of them buying flowers for house warmings and home decorations and they only made $3 \%$ of the purchases for expression of love and $6 \%$ of purchases on Valentine's Day. The differences between male and female buying occasions and recipients' gender helped explain why male buyers were buying a significantly higher proportion of red flowers than female buyers.

The $P$ value of the Hausman test was $<0.001$; therefore, the null hypothesis that the coefficients of the two models were the same was rejected. Because our hypothesis that male and female buyers were similar in their choice of flower colors was rejected, we used two separate multinomial logit models to estimate consumers' choice of flower color for females (Model 1) or males (Model 2). The estimation results are shown in Table 4. To make it easier for readers to read and comprehend the results, Table 4 is divided into three subtables with Table 4-1 showing the results for sociodemographics and year of purchase, Table 4-2 showing the results for noncalendar occasions, and Table 4-3 showing the results for calendar holidays. The Other color category was used as the base color for estimation (the coefficients for Other color category were set to zero). We grouped house warming and home decoration occasions and used these occasions (abbreviated as Decoration) as the reference occasions for estimation (coefficients were set to zero); the results in Table 4-2 and Table 4-3 were relative to the Decoration occasions.

Year and sociodemographics. From the estimation results (as shown in Table 4-1), it was evident that consumers' choice of certain flower colors changed over time. Relative to other colors, female consumers were less likely to choose PeachPink flowers over time, whereas male consumers were less likely to choose RedBronze flowers over time. Income affected consumers' choice of colors as well, affecting female and male buyers differently. Higher-income female buyers tended to purchase more BluePurple, PeachPink, and White single-stem cut flowers and male buyers with higher income levels were less likely to choose Yellow flowers. Age affected consumers' flower color choice. Compared with female consumers who were 39 years old or younger, females who were between ages 40 and 54 years were more likely to choose BluePurple flowers and less likely to choose PeachPink flowers. Compared with males aged 39 years or younger, men between ages 40 and 54 years were less likely to choose White flowers followed by PeachPink flowers. Compared with women aged 39 years or younger, female buyers who were 55 years of age or older were more likely to choose PeachPink and Yellow.

As expected, recipients' gender affected buyers' choice of colors. Female buyers were more likely to choose RedBronze flowers for male recipients and less likely to choose PeachPink for male recipients. Male buyers were most likely to choose BluePurple for male recipients followed by RedBronze and White flowers.

Noncalendar occasions. Table 4-2 shows the estimation results for noncalendar occasions. Both female and male buyers were more likely to choose RedBronze flowers on an anniversary. Additionally, male buyers were also likely to choose PeachPink flowers for an anniversary and least likely to choose BluePurple flowers for this occasion. On birthdays, female buyers were more likely to choose RedBronze followed by PeachPink, Yellow, and White flowers, whereas male buyers were more likely to choose RedBronze followed by PeachPink flowers and less likely to choose BluePurple flowers. For the cemetery/memorial, female buyers were more likely to choose White followed by Yellow, RedBronze, and PeachPink, whereas male shoppers were more likely to choose PeachPink and less likely to choose BluePurple flowers for this occasion. For a get well occasion, both females and males were more likely to choose PeachPink followed by RedBronze flowers. Female buyers were also more likely to choose Yellow and White and BluePurple over other colors. Compared with the house warmings and home decoration occasions, females were more likely to choose White and Yellow flowers for a get well occasion rather than Other colors.

As expected, when people wanted to express love, both males and females were more likely to choose RedBronze flowers. Females ranked Yellow cut flowers second to convey love and PeachPink third, whereas male buyers ranked PeachPink second and Yellow third. Males were less likely to use BluePurple cut flowers to express love. To show sympathy or for a funeral, female buyers were more likely to choose White flowers followed by Yellow, RedBronze, and PeachPink, whereas male shoppers were more likely to choose RedBronze.

Calendar occasions. Table 4-3 shows the consumers' choice of colors on calendar occasions. At Christmas/Hanukkah, both males and females were more likely to choose RedBronze than other colors, and additionally, females were more likely to choose White. Female buyers were least likely to choose Yellow, but both men and women were less likely to choose BluePurple than other colors. Women were also less likely to choose PeachPink than other colors. At Easter/Passover, both female and male shoppers were most likely to choose White followed by Yellow. Female shoppers also chose BluePurple and male shoppers also chose PeachPink and RedBronze. For Mother's Day, both males and females were most likely to choose PeachPink followed by RedBronze. On Valentine's Day, as expected, both male and female were most likely to choose RedBronze followed by PeachPink, and male buyers were least likely to choose BluePurple.

\section{Discussion and Conclusions}

Women still made the majority of floral purchases and were the recipients of most floral gift purchases. Although a higher percentage of male shoppers chose RedBronze, female cut flower buyers chose single stems from a more diverse color palette, because they were more likely to choose flower colors 
Table 4-1. Maximum likelihood estimation results of multinomial logit models on single-stem flower color choices - the coefficients of year and sociodemographics (other color was used as the base color).

\begin{tabular}{|c|c|c|c|c|c|}
\hline \multirow[b]{2}{*}{ Variable } & \multirow[b]{2}{*}{ Color categories } & \multicolumn{2}{|c|}{ Model 1 , female buyers } & \multicolumn{2}{|c|}{ Model 2, male buyers } \\
\hline & & Estimate & SE & Estimate & SE \\
\hline \multirow[t]{5}{*}{ Intercept } & BluePurple & $0.452 * * *$ & 0.124 & $0.793 * * *$ & 0.287 \\
\hline & PeachPink & $1.316^{* * *}$ & 0.113 & $0.877 * * *$ & 0.268 \\
\hline & RedBronze & $1.269 * * *$ & 0.113 & $1.972 * * *$ & 0.249 \\
\hline & White & $0.248 * *$ & 0.125 & 0.347 & 0.293 \\
\hline & Yellow & $0.329 * * *$ & 0.127 & $0.488^{*}$ & 0.290 \\
\hline \multirow[t]{5}{*}{ Year } & BluePurple & 0.017 & 0.011 & 0.029 & 0.021 \\
\hline & PeachPink & $-0.029 * * *$ & 0.010 & -0.010 & 0.018 \\
\hline & RedBronze & -0.002 & 0.010 & $-0.057 * * *$ & 0.017 \\
\hline & White & -0.015 & 0.011 & -0.008 & 0.021 \\
\hline & Yellow & 0.009 & 0.011 & 0.029 & 0.020 \\
\hline \multirow[t]{5}{*}{ Income } & BluePurple & $0.0051 * * *$ & 0.0011 & -0.0005 & 0.0024 \\
\hline & PeachPink & $0.0045 * * *$ & 0.0011 & -0.0004 & 0.0021 \\
\hline & RedBronze & -0.0001 & 0.0011 & -0.0007 & 0.0020 \\
\hline & White & $0.0054 * * *$ & 0.0012 & 0.0003 & 0.0023 \\
\hline & Yellow & 0.0011 & 0.0012 & $-0.0045^{* *}$ & 0.0023 \\
\hline \multirow[t]{5}{*}{ Age $40-54$ years } & BluePurple & $0.117 * *$ & 0.056 & -0.075 & 0.113 \\
\hline & PeachPink & $-0.112 * *$ & 0.052 & $-0.189 * *$ & 0.097 \\
\hline & RedBronze & -0.041 & 0.051 & 0.015 & 0.091 \\
\hline & White & -0.031 & 0.057 & $-0.350 * * *$ & 0.111 \\
\hline & Yellow & 0.049 & 0.058 & -0.169 & 0.108 \\
\hline \multirow[t]{5}{*}{ Age 55 years and older } & BluePurple & -0.036 & 0.057 & -0.128 & 0.116 \\
\hline & PeachPink & $0.129 * * *$ & 0.052 & 0.050 & 0.099 \\
\hline & RedBronze & -0.0001 & 0.051 & -0.115 & 0.094 \\
\hline & White & 0.063 & 0.056 & 0.151 & 0.110 \\
\hline & Yellow & $0.123 * *$ & 0.058 & 0.019 & 0.109 \\
\hline \multicolumn{6}{|l|}{ Receiver's gender } \\
\hline \multirow[t]{5}{*}{ Male } & BluePurple & -0.263 & 0.185 & $1.922 * *$ & 0.815 \\
\hline & PeachPink & $-0.339 * *$ & 0.167 & -0.039 & 0.767 \\
\hline & RedBronze & $0.314 * *$ & 0.157 & $1.546^{* *}$ & 0.752 \\
\hline & White & -0.008 & 0.176 & $1.532 * *$ & 0.795 \\
\hline & Yellow & -0.069 & 0.177 & 0.720 & 0.840 \\
\hline
\end{tabular}

*** significant at the $1 \%$ level; ** significant at the $5 \%$ level; and $*$ significant at the $10 \%$ level $\mathrm{SE}=$ standard error.

Table 4-2. Maximum likelihood estimation results of multinomial logit models on single-stem flower color choices - the coefficients of noncalendar occasions (other color was used as the base color and house warmings and home decoration occasion was used as the reference occasion).

\begin{tabular}{|c|c|c|c|c|c|}
\hline \multirow[b]{2}{*}{ Variable } & \multirow[b]{2}{*}{ Color categories } & \multicolumn{2}{|c|}{ Model 1 , female buyers } & \multicolumn{2}{|c|}{ Model 2, male buyers } \\
\hline & & Estimate & SE & Estimate & SE \\
\hline \multicolumn{6}{|c|}{ Noncalendar occasions } \\
\hline \multirow[t]{5}{*}{ Anniversary } & BluePurple & -0.385 & 0.250 & $-0.790 * * *$ & 0.319 \\
\hline & PeachPink & -0.010 & 0.221 & $0.810^{* * *}$ & 0.289 \\
\hline & RedBronze & $0.454 * *$ & 0.212 & $1.526 * * *$ & 0.267 \\
\hline & White & 0.204 & 0.242 & 0.355 & 0.318 \\
\hline & Yellow & 0.178 & 0.243 & 0.240 & 0.314 \\
\hline \multirow[t]{5}{*}{ Birthday } & BluePurple & 0.045 & 0.129 & $-0.616^{* *}$ & 0.286 \\
\hline & PeachPink & $0.463 * * *$ & 0.119 & $0.695 * * *$ & 0.269 \\
\hline & RedBronze & $0.742 * * *$ & 0.118 & $1.048 * * *$ & 0.250 \\
\hline & White & $0.217 * *$ & 0.135 & 0.405 & 0.293 \\
\hline & Yellow & $0.503 * * *$ & 0.130 & 0.218 & 0.291 \\
\hline \multirow[t]{5}{*}{ Cemetery/memorial } & BluePurple & -0.123 & 0.205 & $-2.323 * * *$ & 0.669 \\
\hline & PeachPink & $0.327 *$ & 0.188 & $2.619 * * *$ & 0.416 \\
\hline & RedBronze & $0.599 * * *$ & 0.183 & 0.353 & 0.426 \\
\hline & White & $0.760 * * *$ & 0.197 & 0.081 & 0.488 \\
\hline & Yellow & $0.723 * * *$ & 0.196 & -0.230 & 0.496 \\
\hline \multirow[t]{5}{*}{ Get well } & BluePurple & $0.449 * *$ & 0.200 & $-0.935^{*}$ & 0.502 \\
\hline & PeachPink & $1.010 * * *$ & 0.186 & $1.308 * * *$ & 0.408 \\
\hline & RedBronze & $0.879 * * *$ & 0.188 & $0.754 * *$ & 0.397 \\
\hline & White & $0.778 * * *$ & 0.203 & 0.341 & 0.465 \\
\hline & Yellow & $0.864 * * *$ & 0.201 & 0.681 & 0.439 \\
\hline \multirow[t]{5}{*}{ Love } & BluePurple & 0.040 & 0.289 & $-0.797 * * *$ & 0.281 \\
\hline & PeachPink & $0.526^{* *}$ & 0.261 & $1.034 * * *$ & 0.258 \\
\hline & RedBronze & $1.138 * * *$ & 0.252 & $1.480 * * *$ & 0.240 \\
\hline & White & 0.168 & 0.300 & 0.013 & 0.293 \\
\hline & Yellow & $0.882 * * *$ & 0.274 & $0.596^{* *}$ & 0.276 \\
\hline \multirow[t]{5}{*}{ Sympathy/funeral } & BluePurple & 0.104 & 0.239 & -0.498 & 0.651 \\
\hline & PeachPink & $0.606 * * *$ & 0.219 & 0.650 & 0.592 \\
\hline & RedBronze & $0.865 * * *$ & 0.216 & $1.082 * *$ & 0.551 \\
\hline & White & $1.582 * * *$ & 0.220 & 0.416 & 0.634 \\
\hline & Yellow & $0.921 * * *$ & 0.230 & 0.735 & 0.608 \\
\hline
\end{tabular}

*** significant at the $1 \%$ level; ** significant at the 5\% level; and *significant at the $10 \%$ level. that were nonred. Over time, a slight decrease in the likelihood that men would buy RedBronze cut flowers occurred, but RedBronze cut flowers still accounted for the majority of male cut flower purchases. On the holiday (Valentine's Day) and occasions (anniversary, love) that are most likely to evoke deep feelings of love, RedBronze flowers were preferred over other colors by both men and women. The strong and traditional preference for red flowers changed little since Hutchison and Robertson (1979) and may be unlikely to change much over the next 30 years. Marketers may suggest other flower colors to potential consumers who may be trying to convey less intense emotions.

Unlike Valentine's Day, both men and women were more likely to select PeachPink flowers over other colors for Mother's Day. By tradition, red is often used at Christmas/ Hanukkah and the red color was the most preferred color theme for tabletop Christmas trees (Behe et al., 2005). This study showed that both men and women were likely to use RedBronze over other flower colors for Christmas/Hanukkah. By tradition, yellow is often used in an Easter/Passover color theme and not surprisingly, both men and women were more likely to select singlestem cut flowers that were Yellow or White.

Even with some similarities, clearly there were differences in flower color preferences for men and women. Although men accounted for only $30 \%$ of the single-stem cut flower transactions, at least $72 \%$ of their floral gifts went to women. Consistently, men were more likely to select RedBronze over other flower colors for single-stem purchases on eight of 10 occasions or holidays, the exceptions being Mother's Day and for a cemetery/memorial occasion. Women were more likely to select RedBronze flowers over other flower colors for an anniversary, birthday, expression of love, Christmas or Hanukkah, and Valentine's Day. Men were not likely to use BluePurple flowers compared with other colors for any holiday or occasion.

Women still made a majority of fresh flower purchases, including single-stem purchases, accounting for $70 \%$ of the transactions. At least $22 \%$ of their purchases go to other women and at least $7 \%$ go to men. However, women are more diverse in the floral color palette, preferring PeachPink and Yellow and White flowers to express sympathy or for funeral, get well, cemetery or memorial, and birthday occasions. They were more likely to use BluePurple flowers compared with men. Because this significant group of floral consumers has a diverse palette, marketers should use multiple colors in marketing and merchandising to keep the diversity of alternatives salient for potential consumers.

Our findings are consistent with some earlier studies on gender and color preferences. Several studies showed that men and women had different color preferences. Ellis and Ficek (2001) found that more males were likely to choose shades of blue as their favorite color, whereas females were more likely to choose pink as their favorite color. The choice 
Table 4-3. Maximum likelihood estimation results of multinomial logit models on single-stem flower color choices - the coefficients of calendar occasions (other color was used as the base color and house warmings and home decoration occasion was used as the reference occasion).

\begin{tabular}{|c|c|c|c|c|c|}
\hline \multirow[b]{2}{*}{ Variable } & \multirow[b]{2}{*}{ Color categories } & \multicolumn{2}{|c|}{ Model 1 , female buyers } & \multicolumn{2}{|c|}{ Model 2, male buyers } \\
\hline & & Estimate & SE & Estimate & SE \\
\hline \multicolumn{6}{|l|}{ Calendar occasions } \\
\hline \multirow[t]{5}{*}{ Christmas/Hanukkah } & BluePurple & $-2.107 * * *$ & 0.223 & $-1.446 * * *$ & 0.490 \\
\hline & Peachpink & $-0.916 * * *$ & 0.147 & 0.313 & 0.378 \\
\hline & RedBronze & $1.170 * * *$ & 0.126 & $1.106 * * *$ & 0.342 \\
\hline & White & $0.351 * * *$ & 0.143 & -0.021 & 0.423 \\
\hline & Yellow & $-2.442 * * *$ & 0.304 & -0.016 & 0.415 \\
\hline \multirow[t]{5}{*}{ Easter/Passover } & BluePurple & $0.300 *$ & 0.160 & 0.217 & 0.474 \\
\hline & Peachpink & 0.222 & 0.154 & $1.005 * *$ & 0.456 \\
\hline & RedBronze & 0.030 & 0.158 & $0.840 *$ & 0.438 \\
\hline & White & $1.511 * * *$ & 0.153 & $2.133 * * *$ & 0.451 \\
\hline & Yellow & $0.851 * * *$ & 0.160 & $1.304 * * *$ & 0.462 \\
\hline \multirow[t]{5}{*}{ Mother's Day } & BluePurple & 0.041 & 0.150 & -0.456 & 0.293 \\
\hline & Peachpink & $0.537 * * *$ & 0.138 & $0.676 * *$ & 0.278 \\
\hline & RedBronze & $0.457 * * *$ & 0.140 & $0.599 * *$ & 0.261 \\
\hline & White & 0.044 & 0.163 & 0.351 & 0.304 \\
\hline & Yellow & -0.025 & 0.163 & -0.137 & 0.310 \\
\hline \multirow[t]{5}{*}{ Valentine's Day } & BluePurple & -0.104 & 0.212 & $-0.847 * * *$ & 0.287 \\
\hline & Peachpink & $0.532 * * *$ & 0.190 & $1.075 * * *$ & 0.262 \\
\hline & RedBronze & $1.402 * * *$ & 0.182 & $1.858 * * *$ & 0.244 \\
\hline & White & 0.277 & 0.215 & 0.288 & 0.291 \\
\hline & Yellow & -0.034 & 0.225 & 0.084 & 0.289 \\
\hline
\end{tabular}

*** significant at the $1 \%$ level; ** significant at the $5 \%$ level and *significant at the $10 \%$ level.

of flower color is more complex given the fact that over time, flowers with different colors have been associated with different symbolic meanings and occasions and a lot of flowers are used as gifts. In addition to considering the symbolic meanings of flowers, the flower givers need to take the receivers' preference as the most important factor instead of their own preference to reduce the risks of gift giving. Because men purchased flowers mostly for women, it is not surprising that they chose the flower color women liked. Similarly, it is reasonable for women to choose the color men like when they buy flowers for men. This explains why women were more likely to choose Blue/Purple flowers than men, that is, more single-stem transactions made by women $(17,192 * 0.07=$ $1,203)$ than those made by men $\left(7,448^{*} 0.02=\right.$ 149) were for male receivers. The results of our research are useful in targeting an audience in advertising and marketing. The findings have important implications for the floral industry on what color of flowers to sell at different occasions to different target markets to cater to consumers' preferences to increase sales. For example, Red/Bronze is the color for anniversaries and Christmas but not BluePurple; White and Yellow are for Easter/ Passover; and PeachPink and RedBronze are for Mothers' Day, Valentine's Day, and get well. It is unlikely that colors tied so closely to traditional holidays and occasions will change much over time. The real opportunity for expanding the fresh flower market likely lies in the noncalendar holidays and occasions, which might have greater potential for popular colors. We found that consumers not only relate different flower colors to different occasions and holidays, but that consumers with different sociodemographic backgrounds tend to choose different flower colors. Besides gender, we also found that consumers' age and income affected their choice of flower colors. For example, we found female consumers who were 40 to 54 years old liked BluePurple flowers than consumers from other age groups, whereas older female consumers who were 55 years and older liked PeachPink more than other age groups. We found female consumers with higher income level liked White, BluePurple, and PeachPink more than other color categories. The results are consistent with earlier work that has shown that consumers of different ages and lifestyles prefer different colors (Saito, 1998). Therefore, if a company's target market is female consumers who are 40 to 54 years old and with higher income, flowers in the BluePurple color category are the right products to source and promote. If a company's target market is female consumers who are 55 years and older and with a higher income level, flowers in the PeachPink color category are the right products to have in stock.

Floral marketers can confidently continue to market red flowers because they comprised a majority of purchases over the 13-year period of this study. However, advertisement that reminds and educates men what types of flower color women prefer and buy for themselves and for other female gift receivers, especially nonred color flowers, may stimulate the demand for other colors.

\section{Literature Cited}

Anonymous. 2008. The color of flowers. 9 Jan. 2008. $<$ http://www.teleflora.com/flowercolors.asp $>$.
Behe, B., R. Nelson, S. Barton, C. Hall, C.D. Safley, and S. Turner. 1999. Consumer preferences for geranium flower color, leaf variegation, and price. HortScience 34:740-742.

Behe, B.K., R.M. Walden, M. Duck, B. Cregg, K. Kelley, and R.D. Lineberger. 2005. Consumer preferences for and cost of production of tabletop Christmas trees. HortScience 40: 409-412.

Birren, F. 1940. Character analysis through color. Crismon, Westport, CT.

Birren, F. 1972. Color psychology and color therapy. Univ. Press, New Hyde Park, NY

Birren, F. 1988. The symbolism of color. Citadel, Secaucus, NJ.

Doyle, K.O., A. Hanchek, and J. McGrew. 1994. Communication in the language of flowers. HortTechnology 4:211-216.

Ellis, L. and C. Ficek. 2001. Color preferences according to gender and sexual orientation. Pers. Individ. Dif. 31:1375-1379.

Greene, W.H. 2002. Econometric analysis. 5th Ed. Prentice-Hall, Upper Saddle River, NJ.

Haviland-Jones, J., H.R. Holly, P. Wilson, and T.R. McGuire. 2005. An environmental approach to positive emotion: Flowers. Ecol. Psychol. 3:104-132.

Hutchison, N.R. and J.L. Robertson. 1979. Consumer demand analysis for roses. J. Amer. Soc. Hort. Sci. 104:303-308.

Kelley, K.M., B.K. Behe, J.A. Biernbaum, and K.L. Poff. 2001. Consumer preference for edible flower color, container size, and price. HortScience 36:801-804.

Kelley, K.M., B.K. Behe, J.A. Biernbaum, and K.L. Poff. 2002. Combinations of colors \& species of containerized edible flowers: Effect on consumer preferences. HortScience 37:218221.

Krech, D., R. Crutchfield, and N. Livson. 1969. Elements of psychology. 2nd Ed. Albert A. Knopf Inc., New York, NY.

Mason, S., T. Starman, R.D. Lineberger, and B.K Behe. 2008. Consumer preferences for price, color harmony and care information of container gardens. HortScience 43:380-384.

Redman, P.B., B.K. Behe, and J.M. Dole. 1997. Consumers prefer red poinsettia cultivars. HortTechnology 7:438-441.

Robertson, J.L. and L.H. Chatfield. 1982. Fresh flower merchandising in loose bunches. HortScience 17:593-595.

Saito, M. 1998. Comparative studies on color preference in Japan and other Asian regions, with special emphasis on the preference for white. Color Res. Appl. 21:35-49.

USDA. 2005. Floriculture and nursery crops situation and outlook yearbook. 15 July 2009. $<$ http://www.ers.usda.gov/Publications/Flo/Jun04/ FLO2004.pdf $>$.

USDA. 2009. Floriculture crops 2008 summary. 15 July 2009. < http://usda.mannlib.cornell.edu/ usda/current/FlorCrop/FlorCrop-04-23-2009. pdf $>$.

Yue, C. and B.K. Behe. 2008. Estimating U.S. consumers' choice of floral retail outlets. HortScience 43:764-769.

Yue, C. and C. Tong. 2009. Organic or local? Investigating consumer preference for fresh produce using a choice experiment with real economic incentives. HortScience 44:366371 . 